\title{
Enhanced Stability Against Radiation Damage of Lysozyme Crystals Grown in Fmoc-CF Hydrogels
}

Rafael Contreras-Montoya ${ }^{\dagger}$ \# Albert Castellvi, Conejero-Muriel, ${ }^{\S}$ Modesto T. Lopez-Lopez, ${ }^{\$}$ Juan M. Cuerva, ${ }^{\dagger}$ Luis Álvarez de Cienfuegos, ${ }^{* \dagger}$ and José A. Gavira*§

† Departamento de Química Orgánica, Facultad de Ciencias, Universidad de Granada, Campus de Fuentenueva, 18002Granada, Spain

* ALBA Synchrotron, Carrera de la Llum 2-26, 08290 Cerdanyola del Vallé,Barcelona, Spain

$\S$ Laboratorio de Estudios Cristalográficos, IACT (Consejo Superior de Investigaciones Científicas-Universidad de Granada), Avenida de las Palmeras 4, 18100 Armilla, Granada, Spain

\$Departamento de Física Aplicada, Facultad de Ciencias, Universidad de Granada, Campus de Fuentenueva, 18002Granada, Spain

\section{Table of Contents}
i) Experimental Section
ii) Figures \& Tables
iii) References 


\section{Experimental Section}

\section{Experimental}

All materials were of analytical grade and used without further purification. Fmoc-Cys-Phe-OH was synthesized by solid phase protocol previously described. ${ }^{1}$

\section{Hydrogel preparation by solvent switch}

Hydrogels Fmoc-CF were prepared in Eppendorf tubes by dissolving the peptide in DMSO followed by the addition of MiliQ water to reach a final volume of $100 \mu \mathrm{L} .^{2}$ The volume relationships DMSO:water depended on the final concentration of the hydrogels being 5:95 for $0.2 \%(\mathrm{w} / \mathrm{v}), 10: 90$ for 0.5 and $0.75 \%(\mathrm{w} / \mathrm{v})$, and 15:85 for 1.0 and $2.0 \%(\mathrm{w} / \mathrm{v})$. The excess of DMSO in the formed hydrogels was then removed by the addition of $1 \mathrm{~mL}$ of MiliQ water on top of the hydrogels, changing the water every day. For TEM and XRD characterization hydrogels were let dried at room temperature to obtain the xerogel sample.

\section{Crystallization experiments}

Lysozyme was purchased as lyophilized powder from Sigma (L6876). Lysozyme was dissolved and dialyzed against $50 \mathrm{mM}$ Sodium Acetate $\mathrm{pH} 4.5$ and the concentration determined spectrophotometrically at 280 prior setting the crystallization experiments and after filtration through a $0.45 \mu \mathrm{m}$ pore size Millipore filter.

Counter-diffusion technique with two layers configuration (2L) of $50 \mu \mathrm{L}$ each, was used to set-up crystallization experiments in Eppendorf tubes ${ }^{3}$. Fmoc-CF, prepared at $1.0 \& 2.0 \%(\mathrm{w} / \mathrm{v})$ were used to set-up the crystallization experiments containing $80 \mathrm{mg} / \mathrm{ml}$ protein concentration and $1.03 \mathrm{M} \mathrm{NaCl}$, everything buffered with $50 \mathrm{mM}$ sodium acetate at $\mathrm{pH} 4.5$.
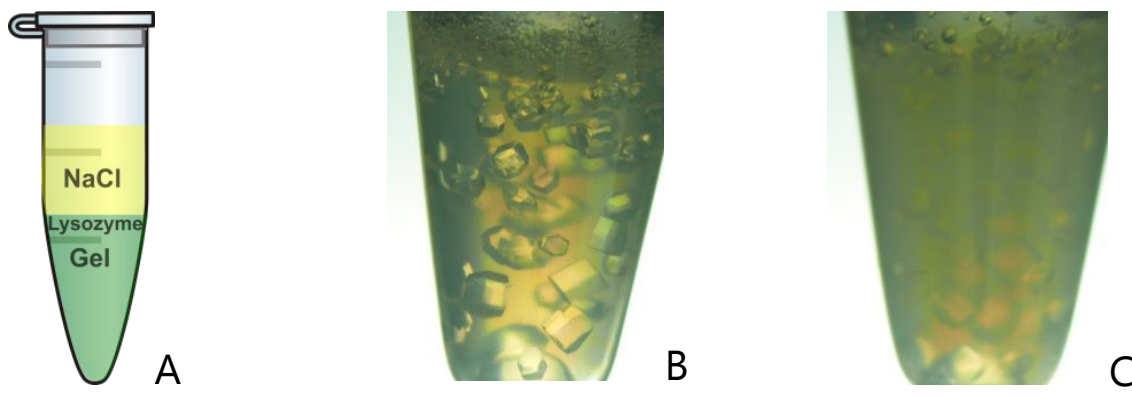

Figure S1. Schematic drawing of the two-layer configuration of the counter diffusion experimental set-up (A) and the results of lysozyme crystals obtained in 1.0 and $2.0 \%$ $(w / v)$ Fmoc-CF hydrogels.

\section{Electron Microscopy (TEM)}

TEM images of xerogels were studied with a LIBRA 120 PLUS Carl Zeiss. A drop of the hydrogel was placed on a 300-mesh copper grid. The sample was dried at room temperature for $30 \mathrm{~min}$.

\section{Circular dichroism (CD)}

The CD spectra were recorded using an Olis DSM172 spectrophotometer with a xenon lamp of $150 \mathrm{~W}$. The hydrogels were gel into a $0.1 \mathrm{~mm}$ quartz cell (Hellma $0.1 \mathrm{~mm}$ quartz Suprasil ${ }^{\circledR}$ ) using the protocols described above. Spectra were obtained from 200 to $320 \mathrm{~nm}$ with a $1 \mathrm{~nm}$ step and $0.1 \mathrm{~s}$ integration time per step at $25^{\circ} \mathrm{C}$. Data shown correspond to the average of 20 measurements.

\section{Fourier transform Infra-red (FTIR) spectroscopy}

Spectra were recorded using a Perkin-Elmer Two FTIR ATR spectrometer. The hydrogels were compressed onto the diamond crystal. All spectra were scanned over the range between 4000 and 450 $\mathrm{cm}^{-1}$. Figure S1. Schematic drawing of the two-layer configuration of the counter diffusion experimental set-up (A) and the re-sults of lysozyme crystals obtained in 1.0 and $2.0 \%$ (w/v) FmocCF hydrogels. 


\section{X-Ray Diffraction (XRD)}

X-ray diffraction (XRD) patterns of xerogels were collected Bruker D2-PHASER diffractometer using CuK $\alpha$ radiation $(\lambda=1.5418 \AA)$ and a LYNXEYE as detector. The $2 \theta$ range was from $3^{\circ}$ to $45^{\circ}$ with a step size of $(2 \theta) 0.02^{\circ}$. The fresh-prepared gels were deposited on a zero diffraction silicon plate and dried overnight at room temperature before the measurement.

\section{Rheological characterization}

We characterized the rheological properties of the NMHG and MHGs by using a Haake MARS III controlled-stress rheometer (Thermo Fisher Scientific, Waltham, MA, USA).

\section{$X$-ray data collection and analysis}

Crystal quality was determined by X-ray diffraction data collected at beam lines BL13-Xaloc $(A L B A)^{4}$ of the Spanish synchrotron radiation sources. Shortly, crystals were extracted from the hydrogel using a pipetman $(200 \mu \mathrm{L})$, with the tip-end cut, and deposited over a plastic Petri dish. Drops of the recovered precipitant or the precipitant plus cryo-protectant $(20 \% \mathrm{v} / \mathrm{v}$ glycerol) were deposited nearby. Selected crystals were transferred to either the precipitant solution, for final cleaning, or directly to the cryo-protectant solution with the help of a LithoLoop (Molecular Dimensions Inc.).

For room temperature data collection lysozyme crystals of aprox. $300 \times 300 \times 300 \mu \mathrm{m}^{3}$ were introduced into a polyimide capillary of $1.0 \mathrm{~mm}$ inner diameter (Goodfellow, IM307100) with the aid of a pipette. Sample dehydration was prevented by keeping a drop of reservoir solution near the crystal. The capillary was sealed with vacuum grease in both extremes and mounted on a SPINE magnetic cap compatible with the diffractometer. Diffraction data sets were collected at the beamline BL13XALOC using a Pilatus 6M photon-counting detector (DECTRIS, Baden, Switzerland). The beam profile had a Gaussian shape and was defocused to a FWHM dimension of $100 \mu \mathrm{m}(\mathrm{h}) \times 53 \mu \mathrm{m}(\mathrm{v})$ as measured by a Ce:YAG fluorescent screen at the sample position. The photon flux was attenuated to $3.45 \cdot 10^{10} \mathrm{ph} / \mathrm{s}(5 \%$ beam transmission) at the sample position as measured using a calibrated PIN Si diode. The sample to detector distance was set to $240 \mathrm{~mm}$.

Lysozyme crystals grown in $0.5 \%(\mathrm{w} / \mathrm{v})$ agarose, $1 \%$ and $2 \%(\mathrm{w} / \mathrm{v})$ Fmoc-CF gels were measured maintaining the same irradiation conditions. For each crystal nine consecutive datasets were collected starting from the same initial angle. Each dataset of 90 images were collected with an angle increment per image of $1^{\circ}$. The average dose in the exposed region (AD-ER) was calculated with RADDOSE3D..$^{5}$ All crystals were assumed to have the same cubic shape with side dimensions of $300 \mu \mathrm{m}$ as measured by the on-beamline microscope. The amount of sulfur atoms in the solvent portion of lysozyme crystals was set to zero. The AD-ER was computed to be $0.03 \mathrm{MGy}$ per dataset.

All datasets were indexed using $\mathrm{XDS}^{6}$ and the values of the relative diffraction intensity $\left(I_{D n} / I_{D 1}\right)$ extracted from XDSSTAT ${ }^{7}$. Each $\mathrm{I}_{\mathrm{Dn}}$ value was calculated in the resolution range between 40 and $1.7 \AA$ . For each dataset, multiple observations of reflections were scaled and merged using AIMLESS ${ }^{8}$ and the final structure factors generated with TRUNCATE (Table S1).${ }^{9}$ For each crystal, structure solution and refinement were systematically performed with the corresponding first dataset (D1) in the resolution range from 40 to $1.35 \AA$ (Table S2). Initial phases were found by molecular replacement with PHASER ${ }^{10}$ and phase refinement were performed with phenix.refine ${ }^{11}$ using anisotropic Bfactors. All phases refinements were considered completed when $R_{\text {work }}$ and $R_{\text {free }}$ reached 0.14 and 0.17 , respectively. Different Fourier maps between D1 and Dn datasets were calculated through the fast Fourier transform of $\left(F_{o b s, D n}-F_{o b s, D 1} ; \alpha D 1\right)$, being $F_{o b s, D n}$ and $F_{o b s, D 1}$ the experimental structure factors from Dn and D1 datasets, respectively, and being $\alpha_{D 1}$ the refined phases from the D1 dataset.

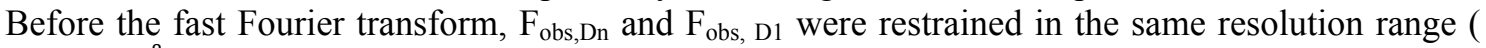
$40-1.7 \AA$ ) and scaled together in two different resolution bins (from 40 to $3.0 \AA$ and from 3.0 to 1.7 $\AA$ ) using SCALEIT (Figure S2-Top). ${ }^{12}$ If the whole range of resolution is used for scale we may introduce errors that are subsequently translated as artefacts in the computed $D n-D 1$ maps (see Figure S2-down as example). The mean difference electron density in $D n-D 1$ should be zero although local differences in electron densities are observed (positive and negative). Fast Fourier transforms were performed with FFT. ${ }^{13}$ Maps and structures were visualized with PyMOL. ${ }^{14}$ 


\section{Figures and Tables}

Table S1. Data collection statistics of lysozyme crystals grown in agarose. For each crystal, the first and the $9^{\text {th }}$ (dark background) datasets were processed in the $40-1.7 \AA$ resolution range to analyze global damage (all) and also for the calculation of $D n-D 1$ maps (agarose and Fmoc-CF, at 0.5 and $2.0 \% \mathrm{w} / \mathrm{v}$, respectively). Values in parentheses are for high resolution shell.

\begin{tabular}{|c|c|c|c|c|c|c|}
\hline $0.5 \%(w / v)$ Agarose & & & & & & \\
\hline Sample & Aga_1 & Aga_1 & Aga_2 & Aga_2 & Aga_3 & Aga_3 \\
\hline Data set & D1 & D9 & D1 & D9 & D1 & D9 \\
\hline Absorbed Dose (MGy) & 0.03 & 0.29 & 0.03 & 0.29 & 0.03 & 0.29 \\
\hline \multicolumn{7}{|l|}{ Data Statistics } \\
\hline Space Group & $\mathrm{P} 4_{3} 2_{1} 2$ & $\mathrm{P} 42_{3} 2$ & $\mathrm{P} 4_{3} 2_{1} 2$ & $\mathrm{P} 4_{3} 2_{1} 2$ & $\mathrm{P} 4_{3} 2_{1} 2$ & $\mathrm{P} 4{ }_{3} 2_{1} 2$ \\
\hline Unit cell $(\mathrm{a}=\mathrm{b}, \mathrm{c})(\AA)$ & $79.18,37.94$ & $79.22,37.94$ & $79.15,37.97$ & $79.20,37.98$ & $79.20,37.95$ & $79.24,37.97$ \\
\hline $\mathrm{I}_{\mathrm{n}} / \mathrm{I}_{1}$ & 1.00 & 0.47 & 1.00 & 0.42 & 1.00 & 0.62 \\
\hline Resolution range ( $\AA$ ) & $\begin{array}{l}39.59-1.70 \\
(1.73-1.70)\end{array}$ & $\begin{array}{l}39.61-1.70 \\
(1.73-1.70)\end{array}$ & $\begin{array}{l}39.57-1.70 \\
(1.73-1.70)\end{array}$ & $\begin{array}{l}39.60-1.70 \\
(1.73-1.70)\end{array}$ & $\begin{array}{l}37.95-1.70 \\
(1.73-1.70)\end{array}$ & $\begin{array}{l}37.97-1.70 \\
(1.73-1.70)\end{array}$ \\
\hline Completeness (\%) & $99.6(99.3)$ & $99.8(99.4)$ & $99.5(99.6)$ & $99.8(99.7)$ & $98.3(99.2)$ & $98.8(98.5)$ \\
\hline Rmeas (\%) & $5.2(7.9)$ & $5.1(32.0)$ & $5.1(8.2)$ & $4.2(39.8)$ & $4.7(8.1)$ & $3.8(38.1)$ \\
\hline Total number of observations & $\begin{array}{l}83149 \\
(4312)\end{array}$ & $\begin{array}{l}87269 \\
(4533)\end{array}$ & $\begin{array}{l}84181 \\
(4525)\end{array}$ & $\begin{array}{l}87847 \\
(4595)\end{array}$ & $\begin{array}{l}83104 \\
(4480)\end{array}$ & $\begin{array}{l}87798 \\
(4509)\end{array}$ \\
\hline$<\mathrm{I} / \sigma>$ & $33.2(21.5)$ & $24.0(5.9)$ & $33.4(21.0)$ & $26.5(5.2)$ & $35.5(22.9)$ & $31.4(6.1)$ \\
\hline $\mathrm{CC}_{1 / 2}(\%)$ & $99.6(99.5)$ & $99.8(99.4)$ & $99.6(99.6)$ & 99.9 (93.7) & 99.7 (99.9) & $99.9(94.8)$ \\
\hline Multiplicity & $6.1(5.9)$ & $6.3(6.2)$ & $6.1(6.2)$ & $6.4(6.3)$ & $6.2(6.2)$ & $6.5(6.3)$ \\
\hline Mosaicity $\left({ }^{\circ}\right)$ & 0.05 & 0.12 & 0.05 & 0.06 & 0.05 & 0.08 \\
\hline
\end{tabular}

\begin{tabular}{|c|c|c|c|c|c|c|}
\hline \multicolumn{7}{|l|}{$1.0 \%(w / v)$ Fmoc-CF } \\
\hline Sample & Fmoc-CF_1 & Fmoc-CF_1 & Fmoc-CF_2 & Fmoc-CF_2 & Fmoc-CF_3 & Fmoc-CF_3 \\
\hline Data set & D1 & D9 & D1 & D9 & D1 & D9 \\
\hline Absorbed Dose (MGy) & 0.03 & 0.29 & 0.03 & 0.29 & 0.03 & 0.29 \\
\hline \multicolumn{7}{|l|}{ Data Statistics } \\
\hline Space Group & $\mathrm{P} 4_{3} 2_{1} 2$ & $\mathrm{P} 42_{3} 2$ & $\mathrm{P} 4_{3} 2_{1} 2$ & $\mathrm{P} 4_{3} 2_{1} 2$ & $\mathrm{P}_{4} 2_{1} 2$ & $\mathrm{P} 4{ }_{3} 2_{1} 2$ \\
\hline Unit cell $(\mathrm{a}=\mathrm{b}, \mathrm{c})(\AA)$ & $79.19,37.97$ & $79.22,37.99$ & $79.20,37.98$ & $79.25,37.99$ & $79.19,37.97$ & $79.25,37.99$ \\
\hline $\mathrm{I}_{\mathrm{n}} / \mathrm{I}_{1}$ & 1.00 & 0.57 & 1.00 & 0.78 & 1.00 & 0.63 \\
\hline Resolution range ( $\AA$ ) & $\begin{array}{l}39.59-1.70 \\
(1.73-1.70)\end{array}$ & $\begin{array}{l}39.61-1.70 \\
(1.73-1.70)\end{array}$ & $\begin{array}{l}39.60-1.70 \\
(1.73-1.70)\end{array}$ & $\begin{array}{l}39.62-1.70 \\
(1.73-1.70)\end{array}$ & $\begin{array}{l}39.60-1.70 \\
(1.73-1.70)\end{array}$ & $\begin{array}{l}39.62-1.70 \\
(1.73-1.70)\end{array}$ \\
\hline Completeness (\%) & $99.4(98.0)$ & $98.0(99.6)$ & $98.9(99.6)$ & $99.5(98.6)$ & $93.6(94.6)$ & $93.7(95.0)$ \\
\hline Rmeas (\%) & $4.4(7.0)$ & $4.1(28.7)$ & $5.2(7.4)$ & $4.1(9.2)$ & $3.9(6.5)$ & $3.6(13.5)$ \\
\hline Total number of observations & $\begin{array}{l}82854 \\
(4241)\end{array}$ & $\begin{array}{l}87443 \\
(4506)\end{array}$ & $\begin{array}{l}82647 \\
(4282)\end{array}$ & $\begin{array}{l}77935 \\
(3414)\end{array}$ & $\begin{array}{l}83704 \\
(4329)\end{array}$ & $\begin{array}{l}85050 \\
(4386)\end{array}$ \\
\hline$<\mathrm{I} / \sigma>$ & $38.2(24.0)$ & $29.9(7.1)$ & $33.5(22.8)$ & $37.1(15.7)$ & $43.8(26.9)$ & $38.8(13.9)$ \\
\hline $\mathrm{CC}_{1 / 2}(\%)$ & $99.7(99.7)$ & $99.9(97.2)$ & $99.6(99.7)$ & $99.8(99.5)$ & $99.8(94.6)$ & $99.9(95.0)$ \\
\hline Multiplicity & $6.0(6.0)$ & $6.4(6.4)$ & $6.0(5.9)$ & $5.7(4.8)$ & $6.5(6.3)$ & $6.6(6.4)$ \\
\hline Mosaicity $\left({ }^{\circ}\right)$ & 0.06 & 0.07 & 0.06 & 0.07 & 0.07 & 0.07 \\
\hline
\end{tabular}




\begin{tabular}{|c|c|c|c|c|c|c|}
\hline \multicolumn{7}{|l|}{$2.0 \%(w / v)$ Fmoc-CF } \\
\hline Sample & Fmoc-CF_1 & Fmoc-CF_1 & Fmoc-CF_2 & Fmoc-CF_2 & Fmoc-CF_3 & Fmoc-CF_3 \\
\hline Data set & D1 & D9 & D1 & D9 & D1 & D9 \\
\hline Absorbed Dose (MGy) & 0.03 & 0.29 & 0.03 & 0.29 & 0.03 & 0.29 \\
\hline \multicolumn{7}{|l|}{ Data Statistics } \\
\hline Space Group & $\mathrm{P} 4_{3} 2_{1} 2$ & $\mathrm{P} 4_{3} 2_{1} 2$ & $\mathrm{P} 42_{3} 2$ & $\mathrm{P} 42_{3} 2$ & $\mathrm{P} 42_{3} 2$ & $\mathrm{P} 4{ }_{3} 2_{1} 2$ \\
\hline Unit cell $(\mathrm{a}=\mathrm{b}, \mathrm{c})(\AA)$ & $79.21,38.00$ & $79.25,38.01$ & $79.23,38.00$ & $79.29,38.02$ & $79.19,37.96$ & $79.22,37.97$ \\
\hline $\mathrm{I}_{\mathrm{n}} / \mathrm{I}_{1}$ & 1.00 & 0.64 & 1.00 & 0.55 & 1.00 & 0.48 \\
\hline Resolution range ( $\AA$ ) & $\begin{array}{l}39.61-1.70 \\
(1.73-1.70)\end{array}$ & $\begin{array}{l}39.62-1.70 \\
(1.73-1.70)\end{array}$ & $\begin{array}{l}39.61-1.70 \\
(1.73-1.70)\end{array}$ & $\begin{array}{l}39.64-1.70 \\
(1.73-1.70)\end{array}$ & $\begin{array}{l}39.59-1.70 \\
(1.73-1.70)\end{array}$ & $\begin{array}{l}39.61-1.70 \\
(1.73-1.70)\end{array}$ \\
\hline Completeness (\%) & $99.8(99.8)$ & $99.9(99.6)$ & $96.0(96.3)$ & $96.8(96.4)$ & $96.8(97.0)$ & $97.1(96.9)$ \\
\hline Rmeas (\%) & $4.3(7.3)$ & $3.7(19.3)$ & $4.0(7.8)$ & $3.9(25.1)$ & $4.3(8.4)$ & $4.2(32.2)$ \\
\hline Total number of observations & $\begin{array}{l}83297 \\
(4411)\end{array}$ & $\begin{array}{l}86947 \\
(4609)\end{array}$ & $\begin{array}{l}83793 \\
(4220)\end{array}$ & $\begin{array}{l}87517 \\
(4429)\end{array}$ & $\begin{array}{l}84624 \\
(4421)\end{array}$ & $\begin{array}{l}87629 \\
(4509)\end{array}$ \\
\hline$<\mathrm{I} / \sigma>$ & $39.0(23.4)$ & $35.8(9.7)$ & $40.1(21.5)$ & $30.7(7.3)$ & $38.5(21.7)$ & $28.7(6.1)$ \\
\hline $\mathrm{CC}_{1 / 2}(\%)$ & 99.7 (99.7) & $99.8(98.6)$ & $99.8(99.6)$ & $99.9(96.5)$ & $99.8(99.6)$ & $99.9(95.5)$ \\
\hline Multiplicity & $6.0(6.1)$ & $6.3(6.4)$ & $6.3(6.1)$ & $6.6(6.4)$ & $6.4(6.3)$ & $6.6(6.5)$ \\
\hline Mosaicity $\left({ }^{\circ}\right)$ & 0.07 & 0.07 & 0.08 & 0.09 & 0.06 & 0.07 \\
\hline
\end{tabular}


Table S2. Data collection and refinement statistics of lysozyme crystals. For each crystal, the first dataset $(D 1)$ was used to calculate the phases employed subsequently for the calculation of $D n-$ D1 maps. Values in parentheses are for the high resolution data shell.

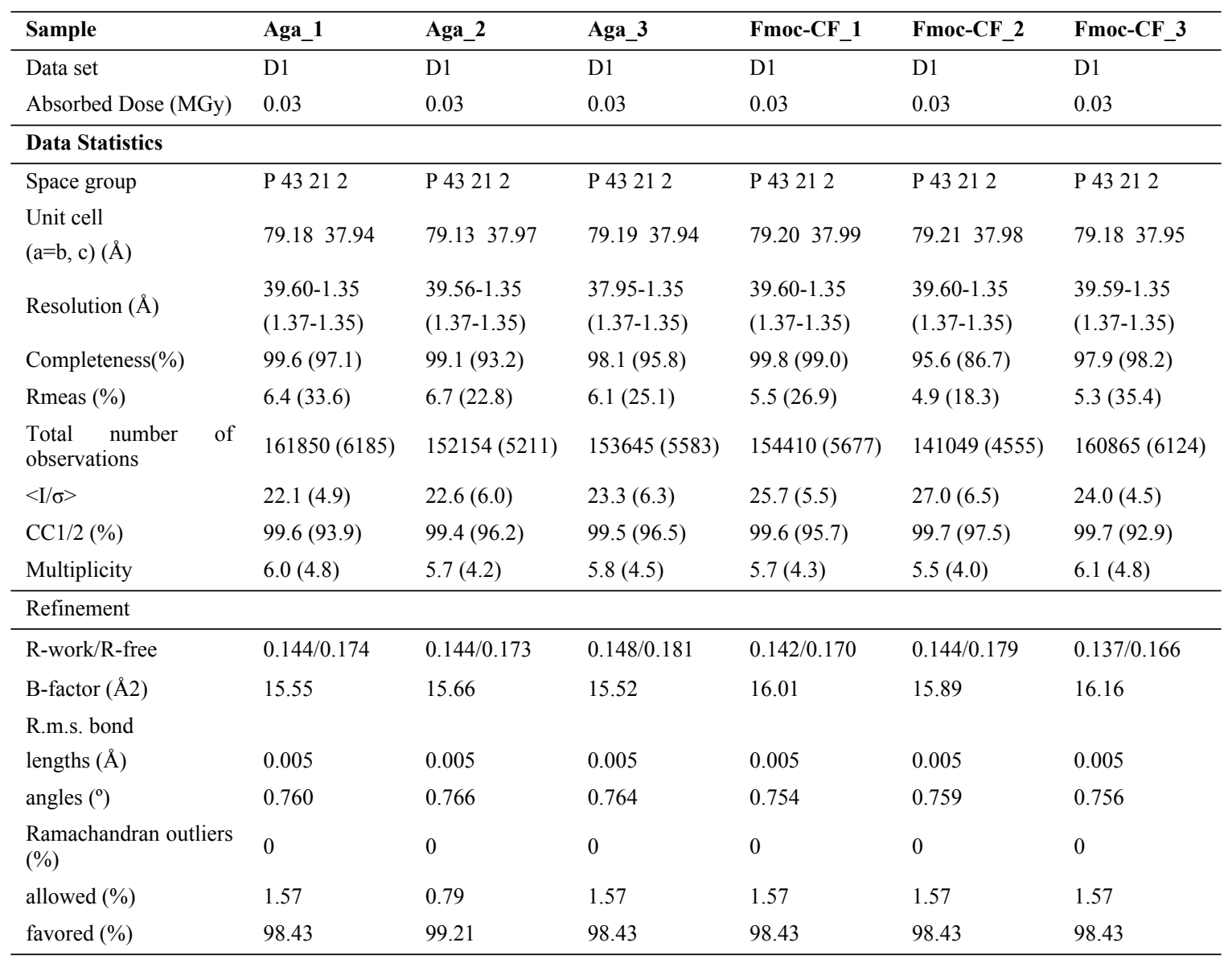




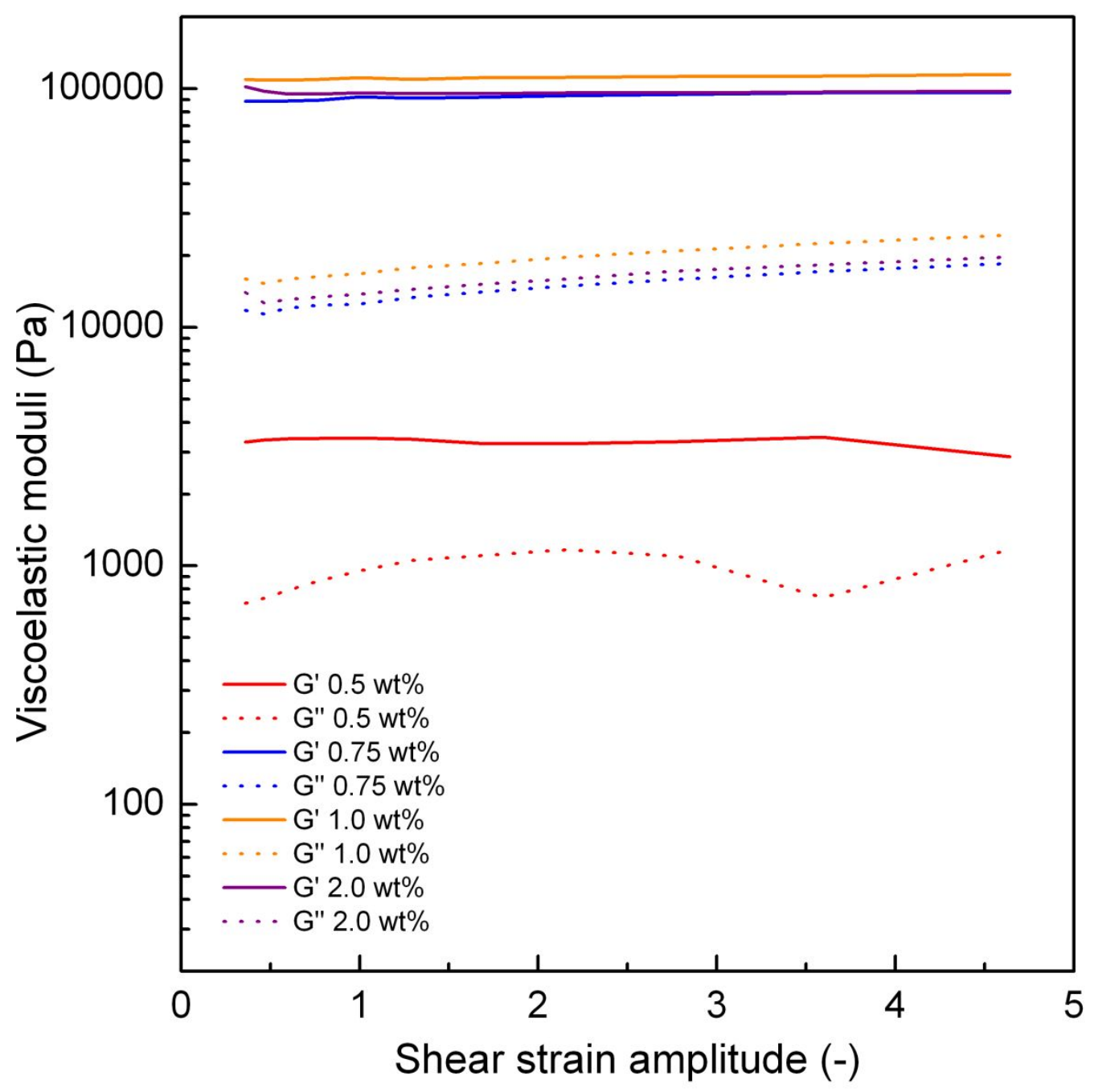

Figure S1. Viscoelastic moduli (G' and G') versus shear strain frequency at a constant shear strain amplitude of $1 \%$, for Fmoc-CF hydrogels. 

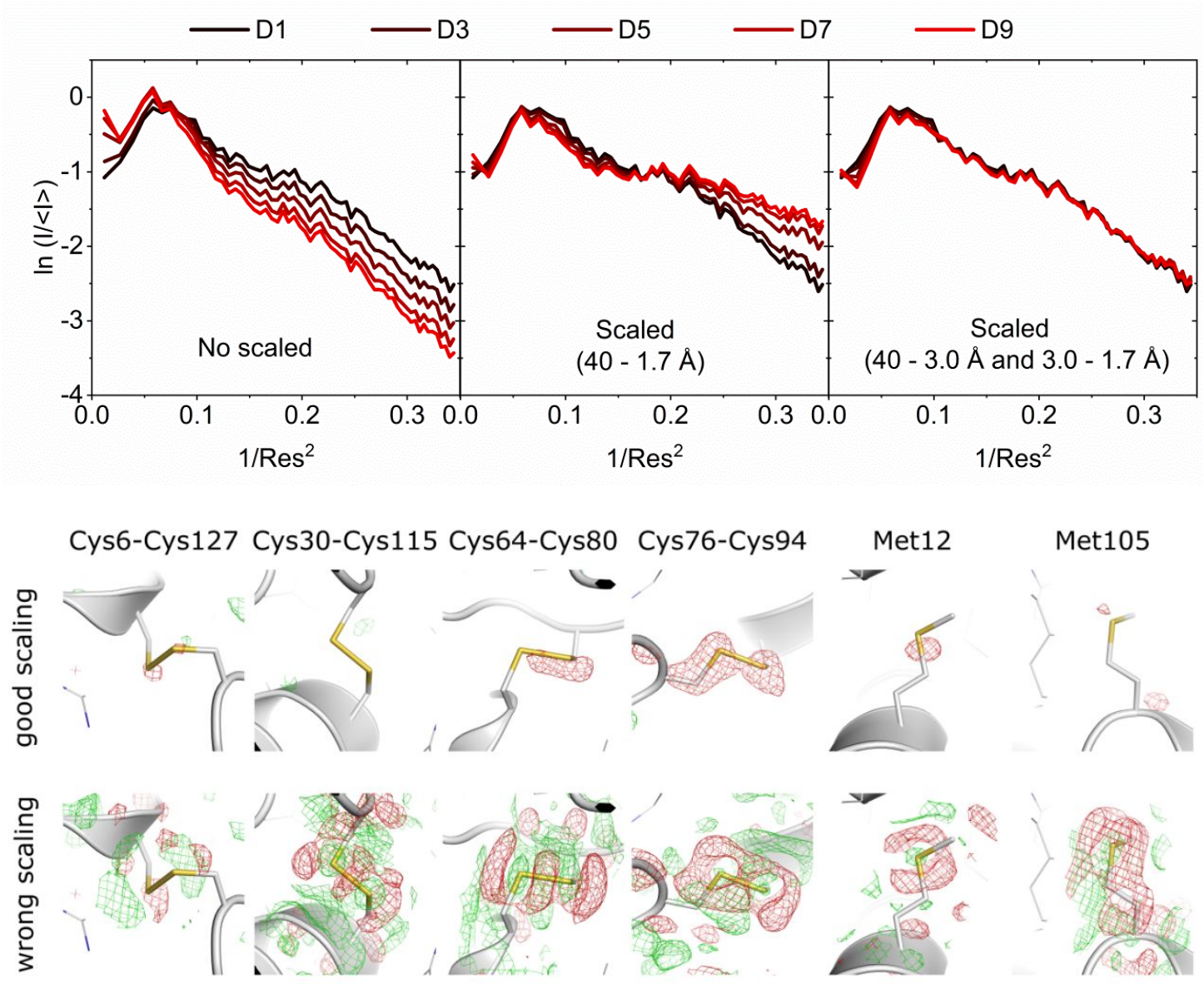

Figure S2. Comparison of the result obtained when considering the entire range of resolution (wrong method) or when divided in two sections (right scaling) and the difference density maps ( $D n-D 1)$ generated from each methodology.

Top. Non-scaled datasets (left), scaled datasets in the $40-1.7 \AA$ resolution range (middle) and scaled datasets in two different resolution ranges (40 - $3.0 \AA$ and $3.0-1.7 \AA$ ) (right). Down. $D 9$ D1 maps over all disulfide bonds and methionines using the right scaling protocol (upper row) and using the wrong scaling protocol (bottom row) for the Aga_1 crystal. All maps are contoured at $\pm 0.15 \mathrm{e} / \mathrm{A}^{3}\left(\mathrm{RMS}_{\text {GoogScaling }}=0.0508, \mathrm{RMS}_{\mathrm{WrongScaling}}=0.07303\right)$. Difference electron density $=\mathrm{RMS}$ $\times \sigma$. Positive and negative difference electron density are plotted in green and red, respectively. 


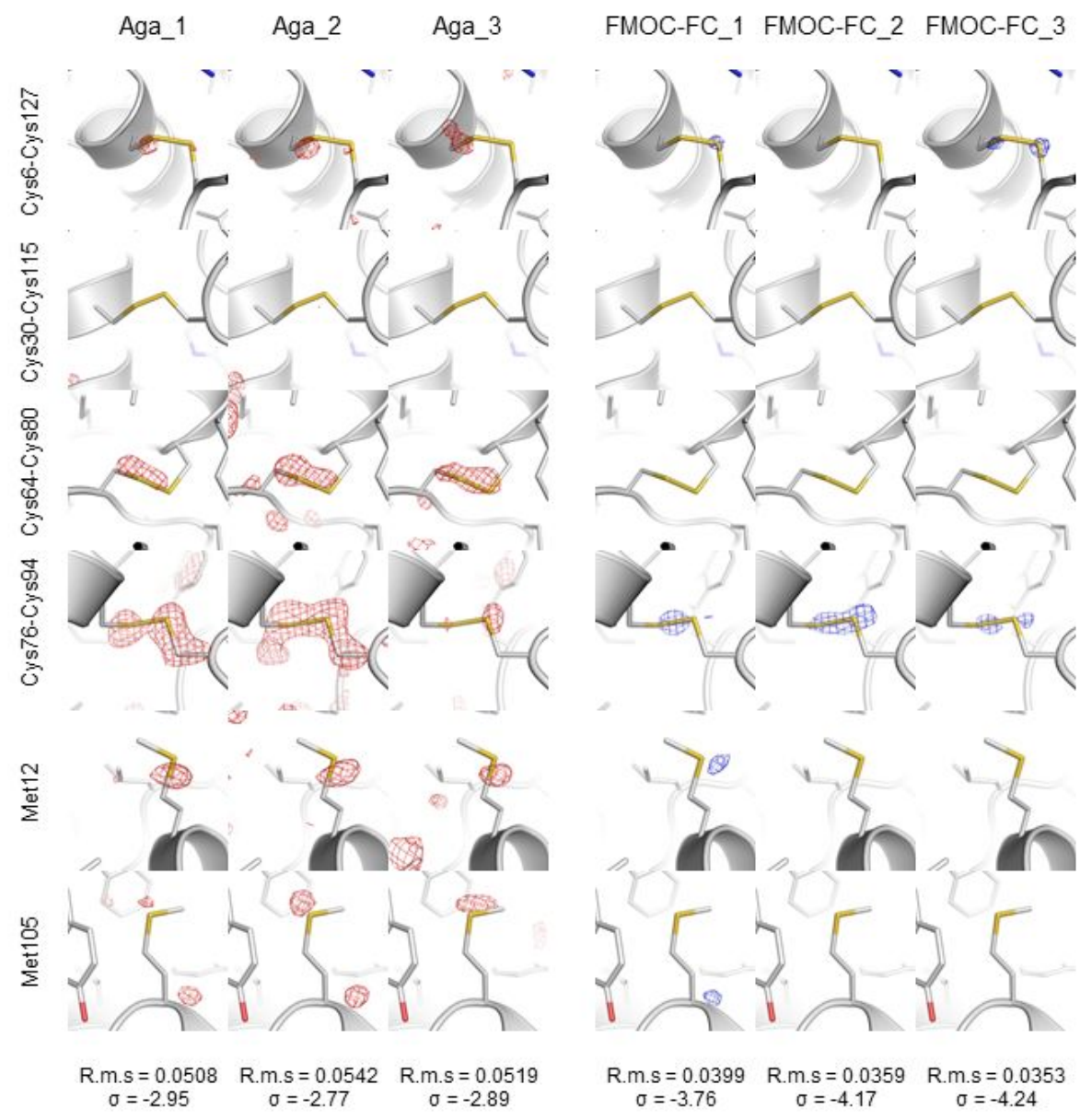

Figure S3. D9-D1 difference maps (blue for Fmoc-FC and red for agarose) over all disulfide bonds and methionines from the six measured lysozyme crystals. It is shown the significant local protection of lysozyme crystals grown in $2.0 \%$ (w/v) Fmoc-FC gel. All maps are contoured at \pm 0.15 $\mathrm{e} / \AA^{3}$ (Difference electron density $=$ RMS $\left.\times \sigma\right)$.

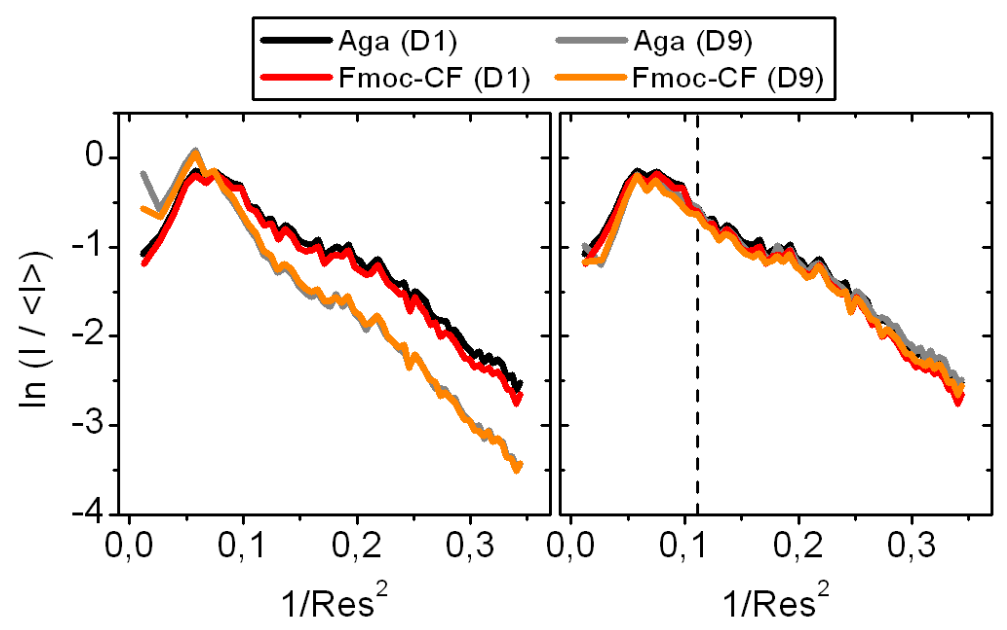

Figure S4. Global and specific damage on lysozyme crystals in presence of agarose and Fmoc-CF hydrogels (b) Wilson plots from D1 and D9 datasets for lysozyme crystals in presence of agarose and Fmoc-CF gels. Left: non-scaled datasets. Right: scaled datasets in two different resolution ranges $(40.0-3.0 \AA$ and $3.0-1.7 \AA)$. Dashed line represents Res $=3.0 \AA$. Data extracted from Aga_1 and Fmoc-FC_1 crystals (see Table S1). 


\section{References}

(1) Conejero-Muriel, M.; Gavira, J. A.; Pineda-Molina, E.; Belsom, A.; Bradley, M.; Moral, M.; Durán, J. d. D. G.-L.; Luque González, A.; Díaz-Mochón, J. J.; Contreras-Montoya, R.; Martínez-Peragón, Á.; Cuerva, J. M.; Álvarez de Cienfuegos, L., Influence of the chirality of short peptide supramolecular hydrogels in protein crystallogenesis. Chem. Commun. 2015, 51, 3862-3865.

(2) Mahler, A.; Reches, M.; Rechter, M.; Cohen, S.; Gazit, E., Rigid, SelfAssembled Hydrogel Composed of a Modified Aromatic Dipeptide. Adv. Mater. 2006, 18, 1365-1370.

(3) Conejero-Muriel, M.; Contreras-Montoya, R.; Díaz-Mochón, J. J.; Álvarez de Cienfuegos, L.; Gavira, J. A., Protein crystallization in short-peptide supramolecular hydrogels: a versatile strategy towards biotechnological composite materials. CrystEngComm 2015, 17, 8072-8078.

(4) Juanhuix, J.; Gil-Ortiz, F.; Cuní, G.; Colldelram, C.; Nicolás, J.; Lidón, J.; Boter, E.; Ruget, C.; Ferrer, S.; Benach, J., Developments in optics and performance at BL13-XALOC, the macromolecular crystallography beamline at the Alba Synchrotron. Journal of Synchrotron Radiation 2014, 21, 679-689.

(5) Zeldin, O. B.; Gerstel, M.; Garman, E. F., RADDOSE-3D: time- and spaceresolved modelling of dose in macromolecular crystallography. J. Appl.

Crystallogr. 2013, 46, 1225-1230.

(6) Kabsch, W., XDS. Acta Crystallogr. Sect. D 2010, 66, 125-132.

(7) Diederichs, K., Some aspects of quantitative analysis and correction of radiation damage. Acta Crystallogr. Sec. D 2005, 62, 96-101.

(8) Evans, P., Scaling and assessment of data quality. Acta Crystallogr. Sec. D 2005, 62, 72-82.

(9) French, S.; Wilson, K., On the treatment of negative intensity observations. Acta Crystallographica Section A 1978, 34, 517-525.

(10) McCoy, A. J.; Grosse-Kunstleve, R. W.; Adams, P. D.; Winn, M. D.; Storoni, L. C.; Read, R. J., Phasercrystallographic software. J. Appl. Crystallogr. 2007, 40, 658-674.

(11) Adams, P. D.; Afonine, P. V.; Bunkóczi, G.; Chen, V. B.; Davis, I. W.; Echols, N.; Headd, J. J.; Hung, L.-W.; Kapral, G. J.; Grosse-Kunstleve, R. W.; McCoy, A. J.; Moriarty, N. W.; Oeffner, R.; Read, R. J.; Richardson, D. C.; Richardson, J. S.; Terwilliger, T. C.; Zwart, P. H., PHENIX: a comprehensive Python-based system for macromolecular structure solution. Acta Crystallogr. Sec. D 2010, 66, 213221.

(12) Howell, P. L.; Smith, G. D., Identification of heavy-atom derivatives by normal probability methods. J. Appl. Crystallogr. 1992, 25, 81-86.

(13) Read, R. J.; Schierbeek, A. J., A phased translation function. J. Appl. Crystallogr. 1988, 21, 490-495. 
(14) Schrodinger, LLC, The PyMOL Molecular Graphics System, Version 1.3r1. In ed.; 2010. 